\section{IN THE NEWS}

Kansas revives evolution Last August, the Kansas Board of Education - urged by conservative Christians removed all references to evolution from the state curriculum, a decision that "'made Kansas an international laughing stock.', Topeka News, US

This February, the Board restored the teaching of evolution to schoolchildren by a 7-to-3 vote.

" 'In a word: hallelujah' said Eugene Scott, director of the National Center for Science Education" in the Los Angeles Times, US.

It became necessary to revise the education standard, "after three national science groups refused to give the Board permission to borrow copyrighted material." Kansas Morning Sun, US

"The new curriculum says that children do not have to accept the theory of evolution, merely to understand it." The Daily Telegraph, UK

One unconvinced Board member objected to: " 'the whole tenor and tone that evolution is a fact.'"

Kansas News, US

And another said:

" 'We need to stop making

evolution a religion."

Kansas News, US

\section{Creationists and} evolutionists are involved in a conflict because of: "'two fundamentally different types of thinking ... Evolutionist proponents believe ... that nature did its own creating. Much of the world doesn't believe that.'” The Washington Post, US

In Kansas, $25 \%$ of biology teachers believe that:

"God designed the earth and all that's in it."

The Washington Post, US

The debate continues.

\title{
GENOME EVOLUTION
}

\section{A well-shuffled deck}

A physical map constructed for a large part of the Drosophila repleta genome has allowed the most comprehensive study of Drosophila genome evolution to date. The conclusion is that the Drosophila genome evolves faster than any other eukaryotic genome - around two orders of magnitude faster than the mammalian genome.

The study focused on chromosome 2 in D. repleta and the equivalent region in Drosophila melanogaster - the right arm of chromosome 3 , which represents about $23 \%$ of the euchromatic portion of the D. melanogaster genome. Around 160 markers, known to map to D. melanogaster chromosome 3R, were used for in situ hybridization against D. repleta polytene chromosomes to construct a physical map of chromosome 2 . The conservation of synteny between the two species was $100 \%$ - all of the markers mapped to chromosome 2 - but strikingly, marker order has been considerably shuffled.

The simplest explanation for the lack of marker order conservation is that many small paracentric inversions have occurred in the Drosophila genome since the divergence of D. melanogaster and D. repleta. Ranz et al. estimate that there have been $\sim 114$ such inversions, and, given the divergence time

\section{MOUSE MODELS}

\section{Unravelling Rett}

Rett syndrome - an inherited, Xlinked neurological disorder - is characterized in females by $7-18$ months of seemingly normal postnatal development, followed by a rapid neurological deterioration that leads to dementia, autism, loss of speech and voluntary movement, and 'acquired' microcephaly. Rett is lethal to males but females can survive these crises and live for several decades.

In 1999, female Rett patients were found to be heterozygous for mutations in MECP2, which encodes a methyl-CpG binding protein that acts as a transcriptional repressor in chromatin remodelling complexes. Mecp2 was then believed to be essential for embryogenesis as attempts to produce mice from Mecp2-null ES cells had failed. This raised a key question: Is Rett a prenatal developmental disorder, which manifests postnatally, or is it due to the malfunctioning of postnatal neurons? Now two papers shed light on this question with the conditional inactivation of Mecp2.

Both groups used Cre-loxP technology to generate mice that lack Mecp 2 by crossing a 'floxed' Mecp 2 allele onto mice that ubiquitously express Cre. The resulting animals produced Mecp2-null offspring of both sexes that were viable and seemingly normal, proving that this gene is not required for embryogenesis. However, by five weeks of age, null mice developed Rett-like movement, breathing and behavioural abnormalities and died around five weeks later. As in female Rett patients, Guy et al. found that neurological deterioration in $M e c p 2^{+/-}$mice took six months to develop, reproducing a key feature of the disease. But the brains of their null mutant mice appeared grossly normal at autopsy, although

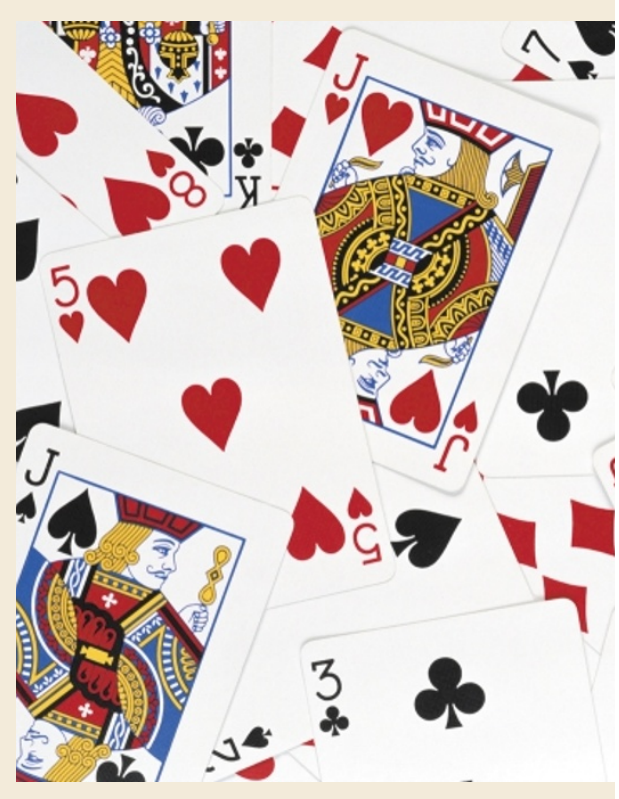

between the species of 80-124 million years, they estimate that around one inversion has been fixed per million years. This greatly exceeds equivalent

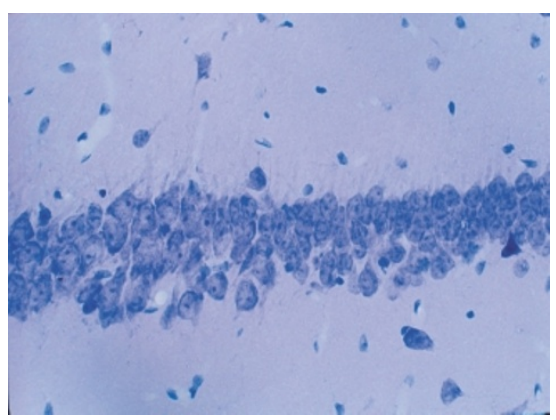

Hippocampal CA1/CA2 neurons from a normal (left) neurons. Courtesy of R. Chen and R. Jaenisch, permission from Nature Genetics (๑) Macmillan

Chen et al. report that their null mutants had brains slightly smaller than normal.

This phenotype is due to the loss of Mecp2 in the brain alone, because mice that lack Mecp 2 mainly in the CNS (generated by expressing Cre from the promoter of the CNS-expressed nestin gene) developed with an identical phenotype to that of the Mecp2-null mice. Neurons in the brains of the null and nestin-Cre Mecp2 mutants had cell bodies and nuclei that were smaller and more closely packed together in certain brain regions than wild-type mice (see picture) 